\title{
Cerebral Angiographic Study of Anatomical Variations of Anterior Cerebral Artery Complex in Bangladeshi Population
}

\author{
MD. AMIR HOSSAIN ${ }^{1}$, SHARIF UDDIN KHAN², KAZIMOHIBUR RAHMAN ${ }^{3}$, \\ SIRAJEESHAFIQUL ISLAM ${ }^{3}$, KHAIRULKABIR PATWARY ${ }^{2}$, DEWAN MD. ELYAS ${ }^{1}$, \\ MUHAMMAD ABDUL MOMEN KHAN ${ }^{1}$, SUVASHKANTI DEY ${ }^{4}$, \\ MD. SHAHIDULLAH ${ }^{4}$, MERINA JAHAN ${ }^{5}$
}

\begin{abstract}
:
Background: Anterior cerebral artery is an important terminal branch of internal carotid artery. It forms the anterior component of circle of Willis along with the anterior communicating artery. It is known for the frequent variations. The knowledge of anatomical variations in anterior cerebral artery is of considerable help to clinicians and interventionists. Method: Morphology and variations of the anterior cerebral arteries and the anterior communicating artery were studied in 90 patients undergone digital subtraction angiography (DSA). Results: Variations were found in 33\% $(n=30)$. Variations of the segments in relation with size, course, communications and terminations of the anterior cerebral artery (ACA) were noted. These were divided into different groups like hypoplasia, aplasia, duplication and fenestrations. Hypoplasia/Aplasia of proximal anterior cerebral artery (A1) was $24.5 \%$ in right side and $9 \%$ in left side. Anterior communicating artery (AComA) was found absent in $9 \%$ and fenestration in $9 \%$. Callosomarginal artery was found absent in $2.2 \%$ in right side and $4.5 \%$ in left side. In right callosomarginal artery $6 \%$ had abnormal origin and $3.5 \%$ abnormal in left side.Pericallosal artery was present $100 \%$ on both sides. Conclusion: Variations of anterior cerebral artery complex anatomy is found common in Bangladeshi population.
\end{abstract}

Key words: Anterior cerebral artery complex, variations, hypoplasia, aplasia, fenestration.

Introduction:

The anterior cerebral artery complex consists of two anterior cerebral arteries (ACA), one anterior communicating artery (AComA) and two recurrent arteries of Heubner. The anatomy of theanterior cerebral artery (ACA) is variable and the description of the ACA and its branches is complicated ${ }^{1}$. Segmentation and branching of the ACA is mostly described similarly bydifferent authors, although the relationship of the pericallosal( $\operatorname{PrcA})$ and callosomarginal arteries $(\mathrm{CmA})$ is not agreed upon $^{2}$. Different branches of ACA are also variable inorigin ${ }^{3}$. Different authors have described thesegments of the ACA differently. It can be divided into proximal or pre-communicatingand distal or post-communicatingsegments. The pericallosal artery is distal to the A1 segment and consists of several segments that can be divided according to its relationship with the corpus callosum ${ }^{4}$. The A2 segment(infracallosal section) runs vertically from the AComA to the genu of the corpus callosum. The A3 segment (precallosal part) curves around the genu, and the A4 segment(supracallosal section) usually runs in the callosal sulcus and almost reaches the splenium ${ }^{5}$. The A5 segment (cortical branches) varies considerably; for this reason it is difficult to describe a standard arterial pattern. The two basic configurations of the ACA are determined by the presence or absence of the $\mathrm{CmA}^{6}$. The different segments of the ACA are

1. Assistant Professor of Neurology, National Institute of Neurosciences and Hospital, Dhaka

2. Associate Professor of Neurology, National Institute of Neurosciences and Hospital, Dhaka

3. Associate Professor of Interventional Neurology, National Institute of Neurosciences and Hospital, Dhaka

4. Associate Professor of Neurology, Bangabandhu Sheikh Mujib Medical University, Dhaka

5. Lecturer, Dhaka Medical College, Dhaka. 
illustrated in Figure 1.Few authors only described three separate segments, namely the $\mathrm{A} 1$ segment (also referred to as the horizontal proximal segment or pre-communicating part), the A2 segment(vertical proximal segment or postcommunicating part) and the $A 3$ segment (the distal segments and cortical branches). The A2 and A3 segments have collectively been referred toas the ascending (or vertical) segment and the A4 and the A5segments as the horizontal segment. The ACA have also been divided into a basal (from the origin to the rostrum of the corpus callosum) and a distal part (runs around genu and above corpus callosum $)^{7}$. Some authors refer to the $A 1$ segment as the ACA and the artery distal to the AComA as the pericallosal artery. A few authors have also referred to the $A 1$ and $A 2$ segments as the ACA, and the artery distal to the origin of the callosomarginal artery, the pericallosal artery ${ }^{8}$. Since the origin of the callosomarginal artery can vary, this terminology can be problematic. The $\mathrm{CmA}$ is also not always present and therefore it is preferable to classify the pericallosal artery as the segment distal to the AComA. Presence of the $\mathrm{CmA}$ artery has been observed in $40.0 \%$ to $93.4 \%$ of specimens. ${ }^{9}$ TheCmA can be due to the different definitions used for this artery. The variability of the absence or presence of the $\mathrm{CmA}$ can be due to the different definitions used for this artery. The ACA complex has a strong clinical importance. It is the most common site of intracranial aneurysm ${ }^{10}$. Despite its considerable significance, little is known about the anatomical variations of the ACA complex ${ }^{11}, 13,14$. Many anomalies such as aplasia, hypoplasia, duplication or fenestration of ACA segments and AComA have been described ${ }^{15}, 16$. Authors used various methods such as digital subtraction angiography (DSA), computed tomography angiography (CTA), Magnetic resonance angiography (MRA), cadaveric dissection or intraoperative observations to study the anterior cerebral circulation of brain. However those studies have a number of limitations. Firstly, they are focused on patients with intracranial aneurysms, and not healthy subjects $17,18,19$. Secondly, the authors base their conclusions on a relatively small study group, rarely exceeding 100 patients. Thirdly, their observations are often limited to the anomalies of the A1 segment (most commonly associated with AComA aneurysms) regardless of AComA and $A 2$ and other segment anomalies ${ }^{1}$. Complete study of anterior cerebral artery complex is lacking in the population of our country. Digital subtraction angiography is now-adays becoming popular minimally invasive angiographic study method for cerebral vessels ${ }^{20,21}$. Most of the pathologies of cerebral vasculature can be explored and treated by Neurointervention methods. The development of Neurointervention is progressively increasing in the field of management of vascular pathologies in brain. So complete understanding by the help of digital subtraction angiography of ACA complex is very important for this population of Bangladesh.

Comparatively few studies describe the anatomy of the ACA complex in subjects without intracranial aneurysms. These are mainly cadaveric studies ${ }^{26}$, 27. There is still a need for further study to explore the anatomy of the anterior cerebral circulation. The results of such studies would be useful when planning neurointerventional procedures and surgical approaches ${ }^{25}$, and would allow avoiding any unexpected anatomical variations during treatment of AComA aneurysms. Such anatomical problems may include double fenestrations of the A2 segment mimicking an aneurysm neck ${ }^{12}$ or mistaking a duplicated $\mathrm{A} 1$ segment for an AComA aneurysm ${ }^{19}$. The aim of this study was to see the common variations of ACA complex configurations by using digital subtraction angiography (DSA).

\section{Materials and Methods:}

This retrospective observational study was conducted in the department of Neurointervention of National Institute of Neurosciences Hospital, Dhaka, Bangladesh during January 2015 to December 2015. All collected data were collected from digital database, checked, edited and analyzed by using computer based SPSS software version 16.0. Data were presented by frequency distribution and percentage.

A total of 90 patientsreffered in the Neurointervention department for digital subtraction 
angiography (DSA)were included in this study. Sampling technique was purposive. The angiogram machine was SIEMENS Artis Zee system and framing rate was $4 \mathrm{f} / \mathrm{sec}$. Angiograms with gross pathology like arteriovenous malformations (AVM) in anterior circulation were excluded from this study. Anterior part of the circle of Willis was studied. Morphological variations, branching pattern and course of the ACA and AComAwere observed. Variations of the size, course, segments, communications and terminations of the anterior cerebral artery complex were noted. These variations were divided into different groups like hypoplasia, aplasia, and duplication of precommunicating segment of ACA (A1), double AComA, fenestrations, azygos ACA and variation in the A2 segment of ACA in its terminal branches. Origin of callosomarginal artery and the course of pericallosal artery were noted and pictures were drawn in data collection sheet.

\section{Results:}

Out of the 90 patients, majority $63(70 \%)$ were belonged to over the age 40 years. And 40 or less than40 years were $27(30 \%)$ (Table I). It was observed $50(55.5 \%)$ were male and $40(44.5 \%)$ were female. Male to female ratio was 5:4 (Table I). Morphologic variationseg. Aplasia/hypoplasia/ fenestration in A1 or AcomA or absent/abnormal origin of callosomarginalartery were present in $30(33 \%)$ of cases. Variations related with the A1 segment of ACA are agenesis, hypoplasia and duplication. Hypo- plastic/ under-developed A1/ Aplastic segment were present in 30 cases. It was seen in $22(24.5 \%)$ on the right and $8(9 \%)$ on the left A1 segment. (Table II).

Table-I

Socio-demographic characteristics of the study patients $(n=90)$

\begin{tabular}{llcc}
\hline Characteristics & $\begin{array}{c}\text { No. of } \\
\text { respondents }\end{array}$ & Percentage \\
\hline Sex & Male & 50 & 55.5 \\
& Female & 40 & 44.5 \\
Age & $\leq 40$ & 27 & 30 \\
& $>40$ & 63 & 70 \\
\hline
\end{tabular}

Table-II

Morphologic variation of $A 1$ segment of $A C A$ on both sides $(n=90)$

\begin{tabular}{lcc}
\hline Right A1 & $\begin{array}{c}\text { Number of } \\
\text { patients }\end{array}$ & Percentage \\
\hline Normal & 68 & 75.5 \\
Hypoplasia/Aplasia & 22 & 24.5 \\
Left A1 & & \\
Normal & 82 & 91 \\
Hypoplasia/Aplasia & 8 & 9 \\
\hline
\end{tabular}

All possible forms of abnormalities of AComA were present in $22(24.5 \%)$ of cases and normal in 68 $(75.5 \%)$ cases. Fenestration of AcomA was seen in $8(9 \%)$ cases, Hypoplastic/ Absent AComA was seen in $8(9 \%)$ cases. Other abnormalities like duplication were present $6(6.5 \%)$ cases. (Table III)

Table-III

Morphologic variation of AComA of ACA complexs $(n=90)$

\begin{tabular}{lcc}
\hline AComA & $\begin{array}{c}\text { Number of } \\
\text { patients }\end{array}$ & Percentage \\
\hline Normal & 68 & 75.5 \\
Fenestration & 8 & 9 \\
Hypoplasia/Aplasia & 8 & 9 \\
Others & 6 & 6.5 \\
\hline
\end{tabular}

Azygos anterior cerebral artery was found in 2 $(2.2 \%)$ cases. Triple A2 segment was found in 1 $(1.1 \%)$ case. Callosomarginal artery was absent in $2(2.2 \%)$ in right side and $4(4.5 \%)$ in left side. Out of them $5(6 \%)$ in right side and $3(3.5 \%)$ in left sidewere abnormal in origin. (Table IVA, IVB)

Pericallosal artery was found in all cases on both sides in this study.

\section{Table IVA}

Morphologic variation of origin of Right Callosomarginal artery $(n=90)$

\begin{tabular}{lcc}
\hline $\begin{array}{l}\text { Right Callosomargina } \\
\text { Artery }\end{array}$ & $\begin{array}{c}\text { Number of } \\
\text { patients }\end{array}$ & Percentage \\
\hline Present & 88 & 97.8 \\
Absent & 2 & 2.2 \\
Origin & & \\
$\quad$ Normal & 83 & 94 \\
$\quad$ Abnormal & 5 & 6 \\
\hline
\end{tabular}


Table-IVB

Morphologic variation of origin of Left Callosomarginal artery $(n=90)$

\begin{tabular}{ccc}
\hline Left Callosomargina & $\begin{array}{c}\text { Number of } \\
\text { patients }\end{array}$ & Percentage \\
\hline Artery & 86 & 95.5 \\
Present & 4 & 4.5 \\
Absent & & \\
Origin & 83 & 96.5 \\
$\quad$ Normal & 3 & 3.5 \\
Abnormal & & \\
\hline
\end{tabular}

Discussion:

Multiple variations in anatomy of anterior cerebral artery complex like agenesis, hypoplasia, fenestrations etc resulting in defective circulation has been reported in the different publications ${ }^{1,8}$. If the artery on one side is narrowed, the vascular insufficiency is compensated by crossing over by opposite side artery, or by giving branches that cross over to the other side. It indicates that the circle of Willis offers a potential shunt in abnormal conditions such as occlusions and spasms. In normal circumstances it is not an equalizer and distributer of blood from different sources. Majority $(70 \%)$ of the study subject wasover 40 years of age, and less than 40 years is $30 \%$. Among them male were $55.5 \%$ and female were $44.5 \%$, and male to female ratio were 5:4. Morphological variations eg. Aplasia/hypoplasia/fenestration in $\mathrm{A} 1$ or AcomA or absent/abnormal origin of callosomarginalartery was present in $30(33 \%)$ of cases. In Text book of Practical Neuroangiography by Pearse Morris, third edition showed the range of variation between $11 \%$ to $43 \%{ }^{2}$. In a cadaveric study Gunnal et al found total variation up to $31.3 \% 30$. Variations related with the $\mathrm{A} 1$ segment of ACA are agenesis, hypoplasia and duplication. Hypo- plastic/ under-developed A1/Aplastic segment were present in 30 cases. It was seen in $22(24.5 \%)$ on the right and $8(9 \%)$ on the left A1 segment. In previous cadaveric study by Riggs and Rupshowed $7 \%$ A1 hypoplasia ${ }^{4}$. Pai et alfound no hypoplasia or aplasia. ${ }^{5}$ ButPiganiol et al found $2.1 \%$ and Macchi et al found it $0.7 \% 6,7$. In a 3DCTA study Niederberger et al showed $10 \%$ hypoplasia/apasia in a series.In general, our study shows a higher percentage of variations. Hypoplasia/Aplasia are more common in right side than the left side $(24.5 \%$ vs8\%).

All possible forms of abnormalities of AComA were present in $22(24.5 \%)$ of cases and normal in 68 $(75.5 \%)$ cases. Fenestration of AcomA was seen in $8(9 \%)$ cases, Hypoplastic/ Absent AComA was seen in $8(9 \%)$ cases. Other abnormalities like duplication were present $6(6.5 \%)$ cases. Autopsy studies described the frequency of fenestrations in the anterior circulation in up to $64.4 \% 25$. Investigations that used three-dimensional digital subtraction angiography (DSA) found a greater incidence of fenestrations in the anterior cerebral circulation, which was $27 \%$ for aneurysm patients and $22 \%$ for patients without aneurysm ${ }^{18}$. On the other hand, Sanders et al. studying 5,190 cerebral angiograms found only 3 fenestrations in the AComA complex. ${ }^{23} \mathrm{~A}$ study by Bozÿek et al. using CTA described the incidence of AComA complex fenestrations to be $1.75 \%^{3}$. Zhao et al, Uchino et aland Saidi et al in cadaveric study found fenestration $0,8 \%, 1.2 \%$ and $26 \%$ respectively ${ }^{13}$, 15,28 , These findings emphasis the fact that twodimensional imaging is not a suitable tool for detecting intracranial arterial fenestrations. The most common anomaly of the anterior cerebral circulation wasfenestratedAComA. Again Cadaveric studies show a vast range of AComA hypoplasia frequency from 9.15 to $30 \% 1,4,7$. In addition, aplastic AComA is a rare autopsy finding, found only in $1.8 \%$ of studied subjects ${ }^{9}$. This phenomenon can be explained by the fact that hypoplastic arteries may notbe hemodynamically efficient, therefore are not visible in angiographic studies and thus are considered to be aplastic. On the other hand, autopsy findings always visualize the artery trunk, even when contrast flow would not be possible. Li et al. using CTA found aplastic AComA's in $9.38 \%$ of study subjects ${ }^{8}$. AComA 3D imaging provides the excellent quality data, but unfortunately it is rarely available in everyday clinical practice ${ }^{20}$. Paiet alshowed $20 \%$ aplastic/ hypoplastic AComA ${ }^{5}$.

Azygos anterior cerebral artery was found in 2 $(2.2 \%)$ cases. In text book Practical Neuroangiography by Pearse Morrisshowed that incidence of azygos ACA is only $0.3 \%^{2}$. Schik et al, 
Dietrich et al, Baptista et aland Kakau et alfound $1.1 \%, 0.5-5 \%, 0-5 \%$ and $0.1-5 \%$ respectively 17,18 , 22. But some study like Osborn et alshowed this value very high (10\%). ${ }^{24}$ In thisstudy we found one $(1.3 \%)$ case of a triple A2 segment. Most authors identify the triple A2 segment as a persistent median artery of corpus callosum, a remnant of embryological cerebral circulation ${ }^{11}$. MRA studies show that the frequency of a triple A2 segment ranges between 0.4 and $3.03 \%{ }^{14,28}$. Usually a triple A2 is an incidental finding. Sun et al. reported a very interesting case of a triple A2 segment associated with the presence of an aneurysm ${ }^{16}$. We have not found such pathology in our study.

Callosomarginal artery was absent in $2(2.2 \%)$ in right side and $4(4.5 \%)$ in left side. Out of them 5 $(6 \%)$ from right sideand $3(3.5 \%)$ from left side wereabnormal in origin. Callosomarginal artery usually originates at the top of the knee of corpus callosum. But very early origin or late origin are also seen. Abnormal origin may be associate with aneurysm formation. The $\mathrm{CmA}$ is also not always present and therefore it is preferable to classify the pericallosal artery as the segment distal to the $\mathrm{AComA}^{17,25}$. The $\mathrm{CmA}$ has been observed in $40.0 \%$ to $93.4 \%$ of specimens ${ }^{6}, 11,17,21.25,27,26$, 29 . The variability of the absence or presence ofthe CmAis due to the different definitions used for this artery by different authors. The $\mathrm{CmAis}$ the largest branch of the pericallosal artery that has been defined as the artery that runs near the cingulate sulcus and gives off two or more cortical branches ${ }^{2}$. But this is problematic since there can occasionally be more than one artery that arises from the pericallosal artery, run in the cingulate sulcus and give rise to a number of cortical branches. Ugur et al. proposed a new classification system ${ }^{29}$. The $\mathrm{CmA}$ was either defined as typical, atypical or absent. Anatypical CmA was observed when there was only a very shortartery coursing in the cingulate sulcus. Two symmetricalcallosomarginal arteries can also be present in the samehemisphere. A typical $\mathrm{CmA}$ has a longer course comparedto the two symmetrical atypical callosomarginal arteries andusually originates from the A3 segment .Ugur et al.observed typical, atypical or absent CmA's in $49 \%, 34 \%$ and $17 \%$ respectively ${ }^{29}$.

\section{Conclusion}

Anterior cerebral artery complex is a common place for anatomical variations and this has a relation with aneurysm formations. The knowledge of these variations will help the clinicians to understand pathophysiology, angioarchitecture and hemodynamics of the lesions in anterior circulation. Morphology and variations of the anterior cerebral artery complex were studied in 90 patients undergone digital subtraction angiography (DSA). Among them $33.3 \%(n=30)$ had different forms ofvariations. Variations of the segments in relation with size, course, communications, origin of callosomarginal arteries, course of pericallosal arteries were noted. These were divided into different groups like hypoplasia, aplasia, duplication and fenestrations. Hypoplasia/Aplasia of proximal anterior cerebral artery (A1) was $24.5 \%$ in right side and $9 \%$ in left side. Anterior communicating artery (AComA) was found absent in $9 \%$ and fenestration in $9 \%$. Callosomarginal artery was absent in $2.2 \%$ in right side and $4.5 \%$ in left side.Whereas, in right callosomarginal artery $6 \%$ had abnormal origin and $3.5 \%$ in left side.Pericallosal arteries were present $100 \%$ on both sides. This study was performed in a small number of subjects. Multicenter studies are necessary to reach a satisfactory conclusion about the complete understanding of anatomy of anterior cerebral artery complex in this population.

\section{References:}

1. Krayenbuhl HA, Yasargil MG. Cerebral angiography. 2nd Ed. New York: Thieme Medical Publishers Inc, 1982:91-3.

2. Morris P. Practical Neuroangiography. $3^{\text {rd }}$ Ed. Philadelphia: Lippincott Williams \& Wilkins, 2013:161-74

3. Bozÿek P, Pilch-Kowalczyk J, Kluczewska E, Zymon-ZagórskaA .Detection of cerebral artery fenestrations by computed tomography angiography. NeurolNeurochir Pol. 2012;46:239-244

4. Riggs HE, Rupp C. Variations in form of Circle of Willis. Arch Neuro/1963; 8(1):8-14.

5. Pai SB, Kulkarni RN, Varma RG. 
Microsurgical anatomy of the anterior cerebral artery-Anterior communicating artery complex: An Indian study. Neurol Asia 2005; 10:21-8.

6. Piganiol $G$, Toga $M$, Paillas J. L'arterecommuni-canteanterieure, Etude embriologiqueetanatomique. Neurochirurgie 1960; 6:3-19.

7. 7.Macchi C, Catini C, Federico C, Gulisano $M$, Pacini $P$, Cecchi F. Magnetic resonance angiographic evaluation of circulusarteriosuscerebri (circle of Willis): a morphologic study in 100 human healthy subjects. Ital $J$ AnatEmbryol1996; 101:115-23.

8. Li Q, Li J, LvF, LiK, Luo T, Xie P.Amultidetector CT angiography study of variations in the circle of Willis in a Chinese population.J ClinNeurosci.2011;18:379-383

9. Maga P, Tomaszewski KA, Pasternak A, Zawilin'ski J, Tomaszewska R, GregorczykMaga I et al. Extra- and intracerebral course of the recurrent artery of Heubner. Folia Morphol (Warsz)2013;72:94-99

10. Maga $\mathrm{P}$, Tomaszewski KA, Skrzat J, Tomaszewska IM, Iskra T, Pasternak A et al.Microanatomical study of the recurrent artery of Heubner. Ann Anat2013;195:342350

11. Gomes FB, Dujovny M, Umansky F, Berman SK, Diaz FG, Ausman JI, Mirchandani HG, Ray WJ.Microanatomy of the anterior cerebral artery.SurgNeurol 1986; 26(2):129-141

12. Compton MR. The pathology of ruptured ACA aneurysms. Lancet 1962; 2:421-38.

13. Zhao HW, Fu J, Lu ZL, Lü HJ. Fenestration of the anterior cerebral artery detected by magnetic resonance angiography. Chin Med $J$ (Engl) 2009; 259

14. Parmar H, Sitoh YY, Hui F. Normal variants of the intracranial circulation demonstrated by MR angiography at 3 T. Eur $J$ Radio/2005;56:220-228.

15. Saidi $H$, Kitunguu $P$, Ogengo JA. Variant anatomy of the anterior cerebral artery in Adult Kenyans.Afr J Neuro/Sci2008; 27:97-105.
16. Sun $C, X v Z D$, Yuan ZG, Wang XM, Wang LJ, Liu C. MSCT diagnosis of aneurysms associated with an unusual variant: atypical triplication anterior cerebral artery. SurgRadiolAnat 2012; 34:777-780.

17. Kakou M, Destrieux C, Velut S. Microanatomy of the pericallosal arterial complex. J Neurosurg2000;93:667-675

18. 18.Dietrich W, Reinprecht $A$, Gruber A, Czech $T$. De novo formation and rupture of an azygospericallosal artery aneurysm. Case report.J Neurosurg2000; 93:1062-4

19. Stefani MA, Schneider FL, Marrone AC, Severino AG, Jackowski AP, Wallace MC. Anatomic variations of anterior cerebral artery cortical branches. ClinAnat2000; 13:231-6.

20. Zurada A, Gielecki J, Shane Tubbs R, Loukas M, Maksymowicz W, Chlebiej M. Detailed 3Dmorphometry of the anteriorcommunicating artery: potential clinical and neurosurgical implications. SurgRadiolAnat2011;33:531538

21. Kedia S, Daisy S, Mukherjee KK, Salunke P, Srinivasa R, Narain MS. Microsurgical anatomy of the anterior cerebral artery in Indian cadavers. Neurol India2013; 61(2):117121

22. Baptista AG. Studies on the arteries of the brain. II. The anterior cerebral artery: Some anatomic features and their clinical implications. Neurology 1963; 13:825-35.

23. Sanders WP, Sorek PA, Mehta BA. Fenestration of intracranial arteries with special attention to associated aneurysms andother anomalies. AJNR Am J Neuroradio/1993;14:675-680

24. Osborn AG. Diagnostic Cerebral Angiography. 2nd Ed. Philadelphia, PA: Lippincott Williams \& Wilkins. Neurology 1999:34-9.

25. Perlmutter D, Rhoton AL. Microsurgical anatomy of the distal anterior cerebral artery. J Neurosurg1978; 49:204-228

26. Ring BA, Waddington MM: Roentgenographic anatomy of the pericallosal arteries. Am J 
Roentgenol Radium TheNuc/Med 1968; 104:109-118

27. Saidi H, Kitunguu PK, Ogeng'OJA.Variant anatomy of the anterior cerebral artery in adult brains. Afr J Neuro/Sci2008; 27(1):97-105

28. Uchino A, Takase Y,Nomiyama K, Egashira $\mathrm{R}$, Kudo S. Fenestration of the middle cerebral artery detected by MR angiography. MagnReson Med Sci2006; 5(1):51-55,
29. Ugur HC, Kahilogullari G, Esmer AF, Combert A, Kanpolat Y. A neurosurgical view of anatomical variations of the distal anterior cerebral artery: An anatomical study. $J$ Neurosurg2006; 104:1-7,

30. Gunnal SA, Wabale RN, FarooquiMS : Variations of anterior cerebral artery in human cadavers: Neurology Asia 2013 ; 18(3): 249259 